Article

\title{
A Microwave-Assisted Simultaneous Distillation and Extraction Method for the Separation of Polysaccharides and Essential Oil from the Leaves of Taxus chinensis Var. mairei
}

\author{
Chunjian Zhao ${ }^{1,2,3}$, Xin He ${ }^{1,2}$, Chunying Li 1,2, , Lei Yang ${ }^{1,2}$, Yujie Fu 1,2,3, Kaiting Wang ${ }^{1,2}$, \\ Yukun Zhang ${ }^{1,2}$ and Yujiao Ni $^{1,2}$ \\ 1 Key Laboratory of Forest Plant Ecology, Ministry of Education, Northeast Forestry University, \\ Harbin 150040, China; zcj@nefu.edu.cn (C.Z.); klp13hx@nefu.edu.cn (X.H.); yanglei@nefu.edu.cn (L.Y.); \\ yujie_fu2002@yahoo.com (Y.F.); klp14wkt@nefu.edu.cn (K.W.); klp14zyk@nefu.edu.cn (Y.Z.); \\ klp14nyj@nefu.edu.cn (Y.N.) \\ 2 State Engineering Laboratory of Bio-Resource Eco-Utilization, Northeast Forestry University, \\ Harbin 150040, China \\ 3 Collaborative Innovation Center for Development and Utilization of Forest Resources, Harbin 150040, China \\ * Correspondence: lcy@nefu.edu.cn; Tel.: +86-451-82190848; Fax: +86-451-82102082
}

Academic Editor: Helmut Martin Hügel

Received: 6 October 2015; Accepted: 8 January 2016; Published: 27 January 2016

\begin{abstract}
An efficient microwave-assisted simultaneous distillation and extraction (MA-SDE) method has been developed for the separation of polysaccharides and essential oil from Taxus chinensis var. mairei. The key operating parameters for MA-SDE were optimized by single factor and central composite design experiments, and the optimal conditions were found to include a particle size of 60-80 mesh, liquid/solid ratio of $22.5 \mathrm{~mL} / \mathrm{g}$, extraction time of $17.5 \mathrm{~min}$, microwave power of $547 \mathrm{~W}$, and dichloromethane was used as the extraction solvent of the essential oil. The yields obtained for polysaccharides and essential oil under the optimized conditions were $6.39 \% \pm 0.12 \%$ and $0.27 \% \pm 0.03 \%$, respectively. The MA-SDE method was also compared with conventional heat reflux extraction (HRE) and hydrodistillation extraction (HDE). The MA-SDE method not only allowed for the simultaneous extraction of polysaccharides and essential oil, but also completed the task with a much shorter extraction time of $17.5 \mathrm{~min}$ (HRE and HDE required 3 and $6 \mathrm{~h}$, respectively). Furthermore, the MA-SDE method gave increased extraction yields for polysaccharides (1.14-fold higher than HRE) and essential oil (1.23-fold higher than HDE). Based on these results, this MA-SDE method represents a rapid and efficient technique for the simultaneous extraction of polysaccharides and essential oil.
\end{abstract}

Keywords: essential oil; microwave-assisted simultaneous distillation/extraction; polysaccharides; Taxus chinensis var. mairei

\section{Introduction}

Taxus chinensis var. mairei is an evergreen conifer native to China, where it is also referred to as "Beauteous Taxus". This plant is a source of active diterpenoids belonging to the taxane class of compounds [1]. The most well-known member of this class is taxol, which is an anti-cancer agent used in the clinic for the treatment of ovarian and breast cancers [2]. With the further study of Taxus, some the other bioactive components with human health benefits, such as, polysaccharide and essential oil were found and have attracted considerable attention throughout the world [3,4].

Recently, the results of numerous reports published have suggested that the polysaccharides from T. chinensis var. mairei possess potent antitumor, antidiabetic, and immunity enhancing activities $[3,5,6]$. 
Furthermore, the essential oils from T. chinensis var. mairei have been reported to exhibit remedial effects in improving sleep quality, resisting consenescence and stabilizing blood pressure [4]. In light of the notable pharmacological activities of the polysaccharides and essential oils derived from plants belonging to the genus Taxus, there is an urgent need for the development of a robust and efficient separation technology to allow them to be studied in greater detail. Unfortunately however, there have been few reports pertaining to the extraction and separation of the polysaccharides or essential oil found in T. chinensis var. mairei.

The polysaccharides and essential oils of plants have traditionally been extracted in separate processes. Conventional heat reflux extraction (HRE) process has been used for the extraction of polysaccharides from plants belonging to the genus Taxus [7]. Microwave-assisted extraction (MAE) has recently been used for the isolation of target ingredients [8,9]. There are several advantages associated with the use of MAE over traditional extraction methods, including better yields, improved extract quality, shorter extraction time and reduced solvent consumption [10]. The results of several studies have shown that MAE is more effective than conventional techniques for the extraction of polysaccharides from plants [11-13]. In these cases, the extraction time and levels of solvent consumption were reduced compared with the conventional techniques, whereas the amount of extracted polysaccharide increased. However, the method can only extract polysaccharides.

The essential oils of a plant can be isolated by traditional hydrodistillation extraction (HDE) [14] or steam distillation extraction [15]. However, the general application of these traditional techniques has been limited by several shortcomings, including the long extraction times and poor recoveries, making them particularly inefficient $[16,17]$. Simultaneous distillation extraction (SDE) using the Likens-Nickerson apparatus effectively combines the advantages associated with liquid-liquid and steam distillation extraction, and its extract efficiency and recovery of volatile compounds was higher than traditional hydrodistillation extraction and steam distillation extraction [18,19]. Several microwave-assisted distillation techniques have recently also been reported for the extraction of essential oils, with satisfactory results being obtained in all cases [20-23]. The operation for microwave assisted distillation-solvent extraction of essential oil was developed [24]. However, the operation can only obtain essential oil.

The aim of this study was to develop an effective method for the simultaneous extraction of polysaccharides and essential oils from T. chinensis var. mairei. Our research group developed a microwave-assisted extraction coupled with hydrodistillation method for simultaneous extraction of essential oils and biphenyl cyclooctene lignans from Schisandra chinensis Baill fruits previously [25]. Considering the advantages of SDE techniques, we improved the previous devices and developed a microwave-assisted simultaneous distillation extraction (MA-SDE) method for synchronous extraction of polysaccharides and essential oils from $T$. chinensis var. mairei.

In this study, experimental design was performed to identify the optimum values for the process variables, including the particle size of the samples, the solvent used for the extraction of the essential oils, the extraction time, microwave power and the liquid/solid ratio. Furthermore, the optimized MA-SDE procedure was compared with conventional extraction techniques for the extraction of the polysaccharides and essential oils from $T$. chinensis var. mairei.

\section{Experimental Section}

\subsection{Chemicals and Reagents}

Analytical grade dichloromethane, chloroform, $n$-hexane, petroleum ether $\left(30-60^{\circ} \mathrm{C}\right)$, diethyl ether, glucose, phenol, sulfuric acid, sodium sulfate anhydrous, and ethanol were obtained from Tianjin Kermel Chemical Reagent Co. Ltd (Tianjin, China).

\subsection{Materials}

Fresh leaves of T. chinensis var. mairei were obtained from Fujian Sansan pharmaceutical Ltd. (Nanping, Fujian, China). The leaves were then dried in the shade at room temperature before being 
milled and passed through 40 mesh, 60 mesh, 80 mesh, and 100 mesh sieves, in turn. The resulting powders were stored in a sealed desiccator at $4{ }^{\circ} \mathrm{C}$ prior to being used.

\subsection{Apparatus}

The MA-SDE device consisted of an MAE system (Shanghai Xintuo Analytical Instruments Co.; Ltd, Shanghai, China) connected to a SDE unit (Shanghai Chaoyue Laboratory Instrument Works Co.; Shanghai, China). A schematic representation of the MA-SDE apparatus used in the current study is shown in Figure 1. The MAE apparatus was operated at an irradiation frequency of $2450 \mathrm{MHz}$ with the output power in the range of 10-800 W and the effect mode of microwave was set as non-pulsed microwave heating. The dimensions of the interior cavity of the oven were $430 \times 512 \times 510 \mathrm{~mm}$, making the oven large enough to accommodate a 500-mL flask.

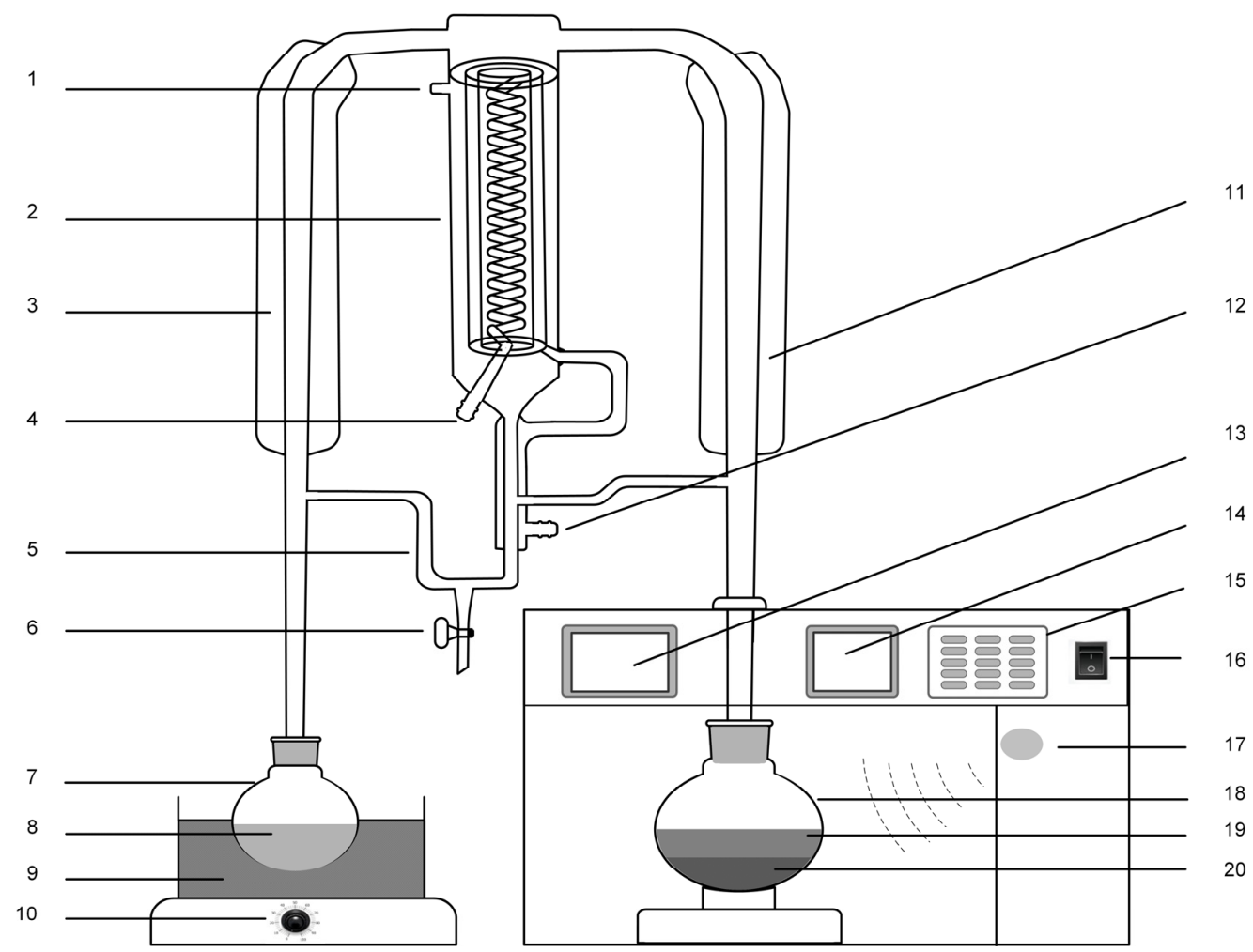

Figure 1. Schematic representation of the MA-SDE device: (1) air-vent; (2) condenser; (3) vacuum tube; (4) water outlet; (5) extraction cell; (6) valve cock; (7) flask I; (8) organic solvents; (9) water bath; (10) power switch; (11) vacuum tube; (12) water inlet; (13) video display; (14) program display; (15) control panel; (16) power switch; (17) microwave generator; (18) flask II; (19) water; and (20) plant materials.

The MA-SDE device is made up of SDE unit and a MAE system. The microwave irradiation can disrupt plant cell walls of plant sample and the phytoconstituents are released into the solvent environment easily [26,27]. Thus, microwave-assisted extraction process can improve extraction of polysaccharides and essential oils. The water in the sample flask and extraction organic solvents are heated to boil, respectively. Then, the water steam with volatile compounds and organic solvents are condensed in the condenser. The volatile compounds are extracted from water into organic solvents in the extraction cell. The organic solvents containing volatile compounds and water will return to each flask through each return arm. Finally, the essential oils are obtained from organic solvent and polysaccharides are obtained from water. In other words, polysaccharides and essential oils are simultaneous extracted from $T$. chinensis var. mairei by the MA-SDE device. 


\subsection{Extraction Procedure}

\subsubsection{Conventional Hydrodistillation Extraction (HDE)}

Twenty grams of the powdered T. chinensis var. mairei leaves were subjected to a conventional HDE procedure in $400 \mathrm{~mL}$ of water for $6 \mathrm{~h}$ (until no more essential oil was obtained) using a Clevenger-type apparatus. Notably, this procedure was conducted in accordance with the method described in the European Pharmacopoeia [28]. This experiment was carried out under atmospheric pressure and the water was heated to boiling.

\subsubsection{Conventional Heat Reflux Extraction (HRE)}

Twenty grams of the powdered T. chinensis var. mairei leaves were placed in a round-bottomed flask followed by $400 \mathrm{~mL}$ of distilled water, and the flask was then placed into a heating mantle and fitted with a reflux condenser before being heated at reflux for $3 \mathrm{~h}$.

\subsubsection{Microwave-Assisted Simultaneous Distillation Extraction (MA-SDE)}

Extraction experiments were carried out using the MA-SDE apparatus illustrated in Figure 1. $50 \mathrm{~mL}$ of an extraction solvent was put into a 100-mL flask (I), and twenty-gram samples of powdered T. chinensis var. mairei leaves were mixed with water in a 500-mL flask (II). In detail, different extraction solvents, including $50 \mathrm{~mL}$ portions of dichloromethane, chloroform, $n$-hexane, petroleum ether $\left(30-60{ }^{\circ} \mathrm{C}\right.$ ) or diethyl ether, were respectively evaluated as extraction solvent in flask (I). The flask (I) was heated in a water bath at $55,72,75,70$, and $45^{\circ} \mathrm{C}$ for dichloromethane, chloroform, $n$-hexane, petroleum ether, and diethyl ether, respectively. At the same time, flask (II) containing a mixture of water and the sample was subjected to microwave irradiation in the oven of the MA-SDE apparatus. After the extraction process, the organic solvent in flask (I) was collected and dried overnight over anhydrous sodium sulfate. The solvent was then removed under reduced pressure to give the essential oil, which was stored at $4{ }^{\circ} \mathrm{C}$ prior to being analyzed. The mixture in flask (II) was centrifuged $\left(10,000 \times g, 5 \mathrm{~min}, 25{ }^{\circ} \mathrm{C}\right)$, and the supernatant was collected and concentrated under reduced pressure. The concentrated solution was then treated with absolute ethanol to give a precipitate, which was collected by filtration and dried at $60{ }^{\circ} \mathrm{C}$ until its weight remained constant and to give crude polysaccharides.

\subsection{Quantification of Polysaccharides and Essential Oil}

The yields of the target analytes in the samples were determined as the average values from three independent experiments. The polysaccharides content in the crude polysaccharides extract was determined by the phenol-sulfuric method using D-glucose as a standard [29]. The polysaccharide yield was calculated according to the following equation [30]:

$$
Y_{1}=W_{1} \times C / W_{2} \times 100
$$

where $\mathrm{Y}_{1}$ is the polysaccharide yield (\%), $\mathrm{W}_{1}$ is the weight of crude polysaccharides $(\mathrm{g}), \mathrm{W}_{2}$ is the weight of the raw material $(\mathrm{g})$ and $\mathrm{C}$ is the polysaccharides content in the crude polysaccharides extract $(\%)$.

The essential oil yield was calculated using the following equation:

$$
Y_{2}=W_{3} / W_{2} \times 100
$$

where $\mathrm{Y}_{2}$ is the essential oil yield (\%), $\mathrm{W}_{2}$ is the weight of the raw material $(\mathrm{g})$, and $\mathrm{W}_{3}$ is the weight of the essential oil $(\mathrm{g})$. 


\subsection{Qualification of Essential Oil by GC-MS}

GC-MS analysis was performed using on a GC system equipped with a GC-MSD 7890 N-5973 insert plus mass spectrometer (Agilent, Santa Clara, CA, USA). The separation of the essential oil was carried out using a HP-5MS capillary column ( $5 \%$ phenyl siloxane $/ 95 \%$ methyl polyorganosiloxane, $30 \mathrm{~m} \times 0.25 \mathrm{~mm} \times 0.25 \mu \mathrm{m})$. Helium was used as the carrier gas, and the flow rate was $1.0 \mathrm{~mL} / \mathrm{min}$. Samples $(1.0 \mu \mathrm{L})$ were injected in splitless mode with a split ratio of 20:1. The temperature of the column was kept at $70{ }^{\circ} \mathrm{C}$ for $3 \mathrm{~min}$, increased to $200^{\circ} \mathrm{C}$ at a rate of $2{ }^{\circ} \mathrm{C} / \mathrm{min}$ and then raised to $240{ }^{\circ} \mathrm{C}$ at a rate of $8{ }^{\circ} \mathrm{C} / \mathrm{min}$. The column was then held at $240^{\circ} \mathrm{C}$ for $5 \mathrm{~min}$ before being raised to $260^{\circ} \mathrm{C}$ at a rate of $5{ }^{\circ} \mathrm{C} / \mathrm{min}$. Finally, the column was then held at $260^{\circ} \mathrm{C}$ for $5 \mathrm{~min}$. The GC-MS connector temperature was kept at $280^{\circ} \mathrm{C}$. The temperature of the ionization source, solvent delay time, and electron energy were set at $230^{\circ} \mathrm{C}, 4 \mathrm{~min}$ and $70 \mathrm{eV}$, respectively. The mass range of the detector was set as $20-400$ atomic mass units $(\mathrm{amu})$.

\subsection{Experimental Design}

The influencing factors, including the solvent used for the extraction of the essential oil, liquid/solid ratio, microwave power, extraction time and particle size of sample, were systematically evaluated using an experimental design process. Based on the single factor experimental results, a $2^{3}$ factorial portion central composite design (CCD) combined with response surface methodology (RSM) was used for optimizing the microwave power $\left(X_{1}: 400-600 \mathrm{~W}\right)$, extraction time $\left(X_{2}: 10-20 \mathrm{~min}\right)$ and liquid/solid ratio $\left(\mathrm{X}_{3}: 15-25 \mathrm{~mL} / \mathrm{g}\right)$. Twenty different experiments with six center points (six replicates for each center point) were used in the CCD test to fit the full quadratic equation model. The general equation was as follows:

$$
Y=\beta_{0}+\sum_{i=1}^{k} \beta_{i} X_{i}+\sum_{i=1}^{k} \beta_{i i} X_{i}^{2}+\sum_{\substack{i=1 \\ i<j}}^{k-1} \sum_{j=2}^{k} \beta_{i j} X_{i} X_{j} \quad(k=3)
$$

where $Y$ represents the response variable; $\beta_{0}, \beta_{i}, \beta_{i i}$, and $\beta_{i j}$ are the regression coefficients of the intercept, linearity, square, and interaction terms, respectively; $X_{i}$ and $X_{j}$ are the independent coded variables affecting the response variable $Y$; and $k$ is the number of variables. Each factor for the test variables was set at one of five different levels (i.e., $-1.68,-1,0,+1,+1.68)$ to evaluate the equation. The dependent variables were set as the yields of the polysaccharides and essential oil from the powdered leaves of $T$. chinensis var. mairei. The actual and coded levels of the independent variables used in the experimental design are shown in Table 1. All of the experiments were conducted in triplicate and the yields reported in the table represent the average values of the three experiments.

Table 1. Experimental conditions used for the central composite design analysis and the corresponding measured responses.

\begin{tabular}{cccccc}
\hline \multirow{2}{*}{ Runs } & \multicolumn{3}{c}{ Factors } & \multicolumn{2}{c}{ Yields (\%) } \\
\cline { 2 - 5 } & $\boldsymbol{X}_{\mathbf{1}}(\mathbf{W})^{\mathbf{a}}$ & $\boldsymbol{X}_{\mathbf{2}} \mathbf{( m i n}^{\mathbf{b}}$ & $\boldsymbol{X}_{\mathbf{3}}(\mathbf{m L} / \mathbf{g})^{\mathbf{c}}$ & Polysaccharides & Essential Oil \\
\hline 1 & $1(600)$ & $1(20)$ & $-1(15)$ & 6.07 & 0.23 \\
2 & $0(500)$ & $0(15)$ & $0(20)$ & 6.22 & 0.27 \\
3 & $0(500)$ & $0(15)$ & $0(20)$ & 6.32 & 0.27 \\
4 & $1(600)$ & $-1(10)$ & $1(25)$ & 6.01 & 0.18 \\
5 & $-1(400)$ & $-1(10)$ & $-1(15)$ & 5.22 & 0.16 \\
6 & $1(600)$ & $1(20)$ & $1(25)$ & 6.34 & 0.25 \\
7 & $-1(400)$ & $1(20)$ & $1(25)$ & 5.77 & 0.24 \\
8 & $1(600)$ & $-1(10)$ & $-1(15)$ & 5.64 & 0.16 \\
9 & $-1(400)$ & $-1(10)$ & $1(25)$ & 5.52 & 0.18 \\
\hline
\end{tabular}


Table 1. Cont.

\begin{tabular}{cccccc}
\hline \multirow{2}{*}{ Runs } & \multicolumn{3}{c}{ Factors } & \multicolumn{2}{c}{ Yields (\%) } \\
\cline { 2 - 5 } & $\boldsymbol{X}_{\mathbf{1}}(\mathbf{W})^{\mathbf{a}}$ & $\boldsymbol{X}_{\mathbf{2}} \mathbf{( m i n}^{\mathbf{b}}$ & $\boldsymbol{X}_{\mathbf{3}} \mathbf{( \mathbf { m L } / \mathbf { g } ) ^ { \mathbf { c } }}$ & Polysaccharides $^{\text {Essential Oil }}$ \\
\hline 10 & $0(500)$ & $0(15)$ & $0(20)$ & 6.15 & 0.27 \\
11 & $-1(400)$ & $1(20)$ & $-1(15)$ & 5.54 & 0.23 \\
12 & $0(500)$ & $0(15)$ & $0(20)$ & 6.33 & 0.26 \\
13 & $-1.68(331.82)$ & $0(15)$ & $0(20)$ & 5.49 & 0.20 \\
14 & $0(500)$ & $0(15)$ & $0(20)$ & 6.12 & 0.27 \\
15 & $1.68(668.18)$ & $0(15)$ & $0(20)$ & 6.27 & 0.20 \\
16 & $0(500)$ & $0(15)$ & $-1.68(11.59)$ & 5.41 & 0.22 \\
17 & $0(500)$ & $-1.68(6.59)$ & $0(20)$ & 5.45 & 0.13 \\
18 & $0(500)$ & $0(15)$ & $1.68(28.41)$ & 5.94 & 0.27 \\
19 & $0(500)$ & $0(15)$ & $0(20)$ & 6.29 & 0.27 \\
20 & $0(500)$ & $1.68(23.41)$ & $0(20)$ & 5.91 & 0.24 \\
\hline
\end{tabular}

${ }^{a} X_{1}$ is expressed as the irradiation power $(\mathrm{W}) ;{ }^{b} X_{2}$ is expressed as the extraction time (min); ${ }^{c} X_{3}$ is expressed as the liquid/solid ratio $(\mathrm{mL} / \mathrm{g})$.

\section{Results and Discussion}

\subsection{Single-Factor Experiments}

\subsubsection{Effect of Extraction Solvent on the Yield of Essential Oil}

Obviously, for MA-SDE, the nature of the extraction solvent could have a significant impact on the yield of the essential oil, but not impact on the yield of the polysaccharides. MA-SDE with different extraction solvent, including hexane, dichloromethane, petroleum ether $\left(30-60^{\circ} \mathrm{C}\right)$, diethyl ether, and chloroform was investigated. Effect of the extraction solvents on the yield of the essential oil obtained from the powdered leaves of T. chinensis var. mairei was seen in Figure 2. It is clear from the results shown in Figure 2 that the use of hexane, petroleum ether, diethyl ether, or chloroform as the extraction solvent resulted in a low yield of the essential oil. In contrast, the use of dichloromethane as the extraction solvent gave much higher yields. The results are consistent with the reference [31]. Based on these results, dichloromethane was identified as the optimum solvent for the extraction of the essential oil from $T$. chinensis var. mairei leaves and used in all of the following experiments.

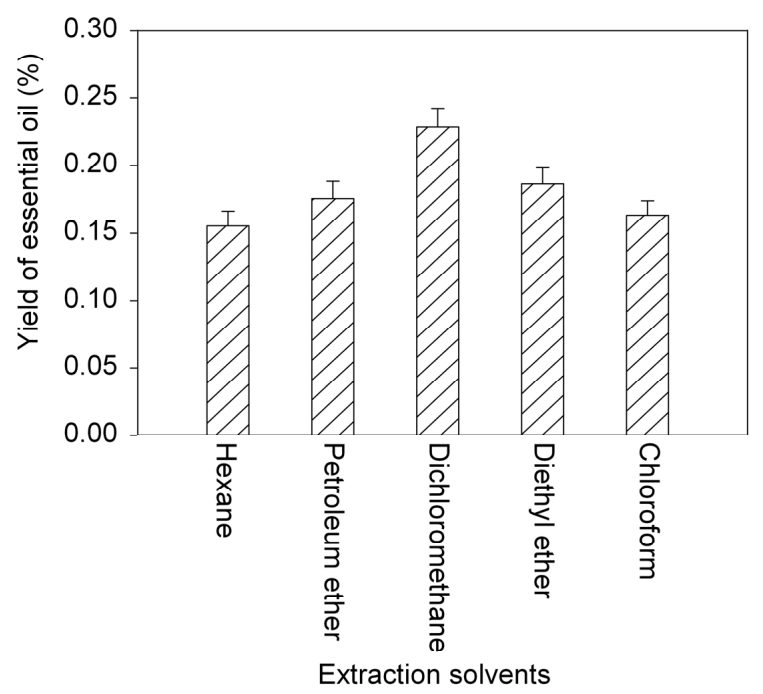

Figure 2. Effect of different extraction solvents on yields of essential oil. Error bars indicate standard deviation $(n=3)$. 


\subsubsection{Effect of Particle Size of Sample}

The particle size of the powdered T. chinensis var. mairei leaves was classified into five fractions using sieves ( $<40$ mesh, 40-60 mesh, 60-80 mesh, 80-100 mesh, and >100 mesh). The effect of the particle size on the extraction yields of the polysaccharides and essential oil are shown in Figure 3A. When the particle size of sample was less than 80 mesh, with the decrease of particle size of the sample, the extraction yields of polysaccharides and essential oil were increased. It can be related to an increase in the specific surface area which allows more contact of the sample with the solvent and a better penetration of the microwave $[32,33]$. However, when the particle size of sample was more than 80 mesh, with the decrease of particle size of the sample, the extraction yields of polysaccharides and essential oil were decreased. It may be smaller particle size was easy to absorb target compounds [34], thus decreasing the diffusion rate of target compounds from sample into solvent. It is clear from the results in Figure 3A that the highest yields of the polysaccharides and the essential oil were obtained when the particle size of the sample was 60-80 mesh.
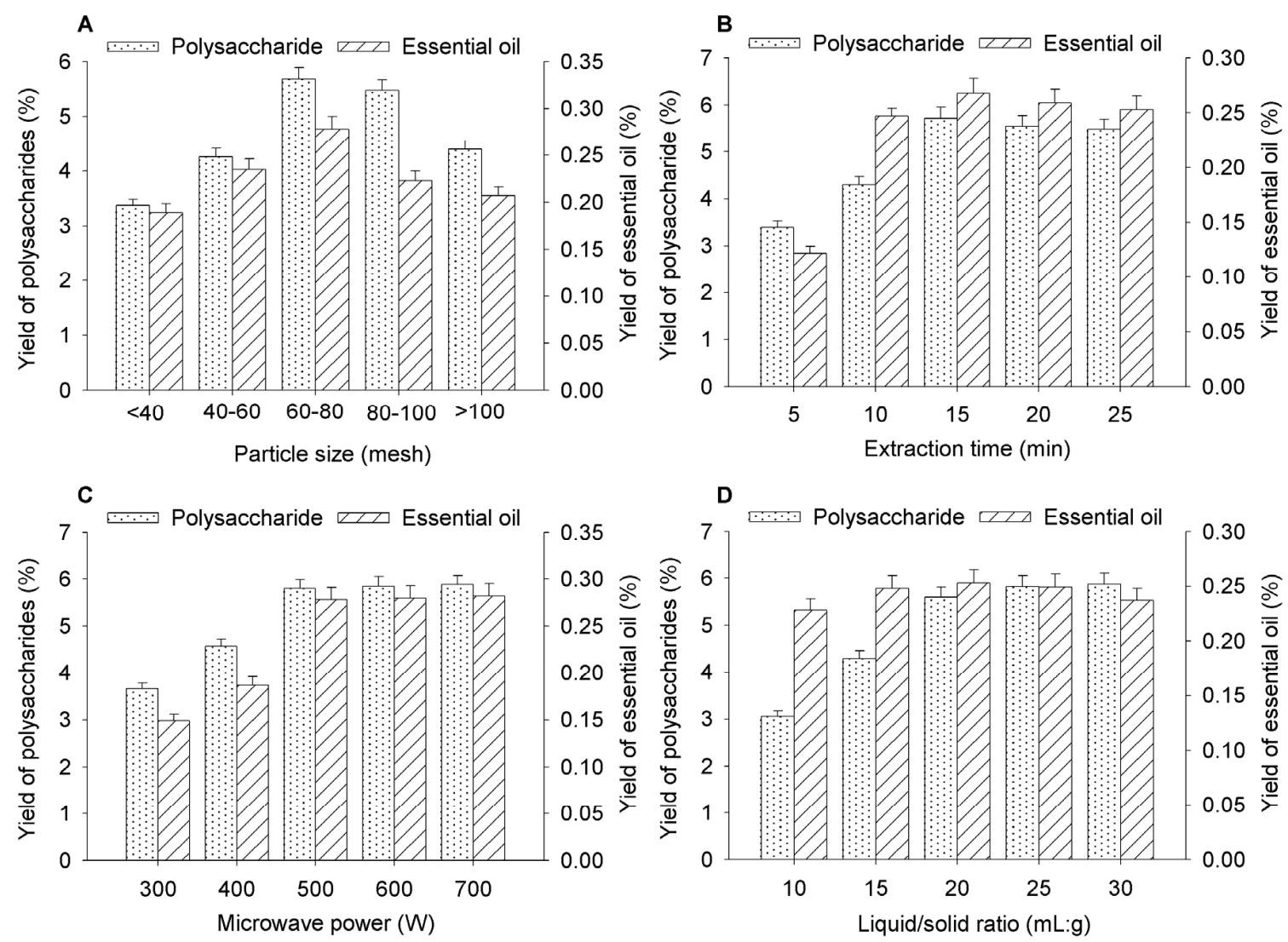

Figure 3. Effects of the different factors on the yields of the polysaccharides and essential oil from T. chinensis var. mairei. (A) effect of particle size of sample; (B) effect of extraction time; (C) effect of the microwave power; (D) effect of liquid/solid ratio. The error bars represent the standard deviation $(n=3)$.

\subsubsection{Effect of Extraction Time}

The effect of extraction time on the yields of the polysaccharides and essential oil was investigated in the range of $5-25 \mathrm{~min}$. Based on the results shown in Figure 3B, it is clear that the yields of the polysaccharides and essential oil increased significantly as the extraction time was increased from 5 to $15 \mathrm{~min}$. However, further increasing the extraction time from 15 to $25 \mathrm{~min}$ led to a slight decrease in the yields of polysaccharides and essential oil. This decrease in the yields following an extended 
extraction time could be attributed to the decomposition of polysaccharides and essential oil under the high temperatures required of the extraction process, resulting in a decrease in their yield. Based on these results, an extraction time of $15 \mathrm{~min}$ was identified as the optimum extraction and used for the subsequent experiments.

\subsubsection{Effect of the Microwave Power}

The microwave power was found to have a significant effect on the yields of the target compounds from the powdered leaves of T. chinensis var. mairei (see Figure 3C). When the microwave power was increased from 300 to $500 \mathrm{~W}$, the yields of the target compounds increased significantly. This increase in the yields was attributed to the fact that microwave irradiation energy can enhance the extent to which the solvent penetrates into the solid matrix of the powdered sample [35]. In this way, the solvent can be efficiently delivered to the target compounds through molecular interaction with the electromagnetic field, allowing for the rapid transfer of energy to the solvent and matrix and the facile extraction of the dissolved components [36]. However, the too high power may lead to loss of volatile oil and degradation of polysaccharides [37]. When the microwave power was beyond $500 \mathrm{~W}$, the yields of essential oil and polysaccharides leveled off, which is probably because that the extraction and degradation of target compounds arrive a balance at this circumstance. Hence, the optimal microwave power was determined to be $500 \mathrm{~W}$ and used in the subsequent reactions.

\subsubsection{Effect of Liquid/Solid Ratio}

A series of extractions were performed with different liquid/solid ratios to evaluate the effect of the liquid/solid ratio on the yields of the polysaccharides and essential oil. Figure 3D shows that the yields of the polysaccharide and essential oil significantly increased when the liquid/solid ratio was increased from 10 to $20 \mathrm{~mL} / \mathrm{g}$. When the liquid/solid ratio was varied from 20 to $30 \mathrm{~mL} / \mathrm{g}$, there was no discernible difference in the yields of target compounds. Based on these results, the optimal liquid/solid ratio was determined to be $20 \mathrm{~mL} / \mathrm{g}$ and used for the subsequent experiments.

\subsection{Optimization of the Extraction by RSM}

The individual and combined effects of these factors on the efficiency of the isolation procedure can be estimated by statistical methods such as RSM [38]. According to the results of the single-factor experiments, three major parameters, including the microwave power, extraction time and liquid/solid ratio were further optimized by CCD combined with RSM. The center points were set as $500 \mathrm{~W}$ (microwave power), $15 \mathrm{~min}$ (extraction time), and $20 \mathrm{~mL} / \mathrm{g}$ (liquid/solid ratio), and the results are shown in Table 1. Regression analyses were conducted to fit the models of the experimental data form Table 1. A second-order polynomial model was used to express the yields of the polysaccharides and essential oil, and two equations with the three independent variables are as follows:

$$
\begin{aligned}
Y_{1}=-3.25+1.22 \times 10^{-2} X_{1}+0.25 X_{2}+0.33 X_{3}+4.75 \times 10^{-5} X_{1} X_{2}+2.75 \times 10^{-5} X_{1} X_{3} \\
-8.50 \times 10^{-5} X_{2} X_{3}-2.50 \times 10^{-6} X_{1}^{2}-1.20 \times 10^{-3} X_{2}^{2}-3.50 \times 10^{-4} X_{3}^{2} \\
Y_{2}=-0.88+2.39 \times 10^{-3} X_{1}+4.25 \times 10^{-2} X_{2}+1.59 \times 10^{-2} X_{3} \\
+ \\
+2.50 \times 10^{-6} X_{1} X_{2}+2.50 \times 10^{-6} X_{1} X_{3}+5.00 \times 10^{-5} X_{2} X_{3} \\
-1.15 \times 10^{-5} X_{1}^{2}-7.45 \times 10^{-3} X_{2}^{2}-7.52 \times 10^{-3} X_{3}^{2}
\end{aligned}
$$

where $Y_{1}$ and $Y_{2}$ are the yields of the polysaccharide and essential oil (\%), respectively; $X_{1}$ is the microwave power $(\mathrm{W}) ; X_{2}$ is the extraction time ( $\left.\mathrm{min}\right)$; and $X_{3}$ is the liquid/solid ratio $(\mathrm{mL} / \mathrm{g})$.

The significance of each coefficient was determined based on the results of an $F$ test and the corresponding $p$-values, as well as the results of variance analysis (ANOVA) for the quadratic model, as shown in Tables 2 and 3. A large $F$-value with a small $p$-value indicated that the corresponding term in the model was more likely to be significant. The coefficient $\left(r^{2}\right)$ obtained from the calculated 
model was 0.9836 for the polysaccharides and the lack-of-fit $(p>0.05)$ was not found to be significant. The coefficient $\left(r^{2}\right)$ obtained from the calculated model was 0.9941 for the essential oil and the lack-of-fit $(p>0.05)$ was not found to be significant.

Table 2. ANOVA of response surface quadratic model for extraction yield of polysaccharides from T. chinesis var. mairei.

\begin{tabular}{cccccc}
\hline Source & Sum of Squares & DF & Mean Square & F-Value & $p$-Value \\
\hline Block & $2.19 \times 10^{-2}$ & 1 & $2.19 \times 10^{-2}$ & - & - \\
Model & 2.47 & 9 & 0.27 & 59.88 & 0.00 \\
$X_{1}$ & 0.81 & 1 & 0.81 & 176.41 & 0.00 \\
$X_{2}$ & 0.32 & 1 & 0.32 & 70.75 & 0.00 \\
$X_{3}$ & 0.31 & 1 & 0.31 & 67.93 & 0.00 \\
$X_{1} X_{2}$ & $4.51 \times 10^{-3}$ & 1 & $4.51 \times 10^{-3}$ & 0.99 & 0.35 \\
$X_{1} X_{3}$ & $1.51 \times 10^{-3}$ & 1 & $1.51 \times 10^{-3}$ & 0.33 & 0.58 \\
$X_{2} X_{3}$ & $3.61 \times 10^{-3}$ & 1 & $3.61 \times 10^{-3}$ & 0.79 & 0.40 \\
$X_{1}^{2}$ & 0.19 & 1 & 0.19 & 42.05 & 0.00 \\
$X_{2}{ }^{2}$ & 0.50 & 1 & 0.50 & 109.19 & 0.00 \\
$X_{3}^{2}$ & 0.51 & 1 & 0.51 & 111.27 & 0.00 \\
Residual & 0.041 & 9 & $4.58 \times 10^{-3}$ & - & - \\
Lack of fit & $4.67 \times 10^{-3}$ & 5 & $9.34 \times 10^{-4}$ & 0.10 & 0.99 \\
Pure error & 0.037 & 4 & $9.14 \times 10^{-3}$ & - & - \\
Cor total & 2.53 & 19 & - & - & - \\
\hline
\end{tabular}

As shown in Table 2, the model terms with significant effects on the polysaccharide yields $(p<0.01)$ were determined to be the linear terms of $X_{1}, X_{2}$, and $X_{3}$, and the quadratic terms of $X_{1}^{2}, X_{2}{ }^{2}$, and $X_{3}{ }^{2}$, while the interaction terms $\left(X_{1} X_{2}, X_{1} X_{3}\right.$, and $\left.X_{2} X_{3}\right)$ were not significant $(p>0.05)$.

Table 3. ANOVA of response surface quadratic model for the extraction yield of the essential oil from T. chinensis var. mairei.

\begin{tabular}{cccccc}
\hline Source & Sum of Squares & DF & Mean Square & F-Value & $p$-Value \\
\hline Block & 0.00 & 1 & 0.00 & - & - \\
Model & $3.71 \times 10^{-2}$ & 9 & $4.12 \times 10^{-3}$ & 168.37 & 0.00 \\
$X_{1}$ & $7.32 \times 10^{-6}$ & 1 & $7.32 \times 10^{-6}$ & 0.30 & 0.60 \\
$X_{2}$ & $1.52 \times 10^{-2}$ & 1 & $1.52 \times 10^{-2}$ & 619.48 & 0.00 \\
$X_{3}$ & $1.74 \times 10^{-3}$ & 1 & $1.74 \times 10^{-3}$ & 71.05 & 0.00 \\
$X_{1} X_{2}$ & $1.25 \times 10^{-5}$ & 1 & $1.25 \times 10^{-5}$ & 0.51 & 0.50 \\
$X_{1} X_{3}$ & $1.25 \times 10^{-5}$ & 1 & $1.25 \times 10^{-5}$ & 0.51 & 0.50 \\
$X_{2} X_{3}$ & $1.25 \times 10^{-5}$ & 1 & $1.25 \times 10^{-5}$ & 0.51 & 0.50 \\
$X_{1}{ }^{2}$ & $8.84 \times 10^{-3}$ & 1 & $8.84 \times 10^{-3}$ & 361.15 & 0.00 \\
$X_{2}{ }^{2}$ & $1.30 \times 10^{-2}$ & 1 & $1.30 \times 10^{-2}$ & 532.33 & 0.00 \\
$X_{3}{ }^{2}$ & $1.13 \times 10^{-3}$ & 1 & $1.13 \times 10^{-3}$ & 46.23 & 0.00 \\
Residual & $2.20 \times 10^{-4}$ & 9 & $2.45 \times 10^{-5}$ & - & - \\
Lack of fit & $1.45 \times 10^{-4}$ & 5 & $2.90 \times 10^{-5}$ & 1.55 & 0.35 \\
Pure error & $7.52 \times 10^{-5}$ & 4 & $1.88 \times 10^{-5}$ & - & - \\
Cor total & $3.73 \times 10^{-2}$ & 19 & - & - & - \\
\hline
\end{tabular}

As shown in Table 3, the model terms with significant effects on the yield of the essential oil $(p<0.01)$ were determined to be the linear terms of $X_{2}$ and $X_{3}$, and the quadratic terms of $X_{1}{ }^{2}, X_{2}{ }^{2}$ and $X_{3}{ }^{2}$, while the interaction terms $\left(X_{1} X_{2}, X_{1} X_{3}\right.$, and $\left.X_{2} X_{3}\right)$ and the linear term of $X_{1}$ were not significant $(p>0.05)$.

Three dimensional response surfaces show the effects of the mutual interactions between the independent variables. The yields of the polysaccharides and essential oil were predicted for the 
different values of the test variables and the interactions between the microwave power, extraction time and liquid/solid ratio (see Figure 4).
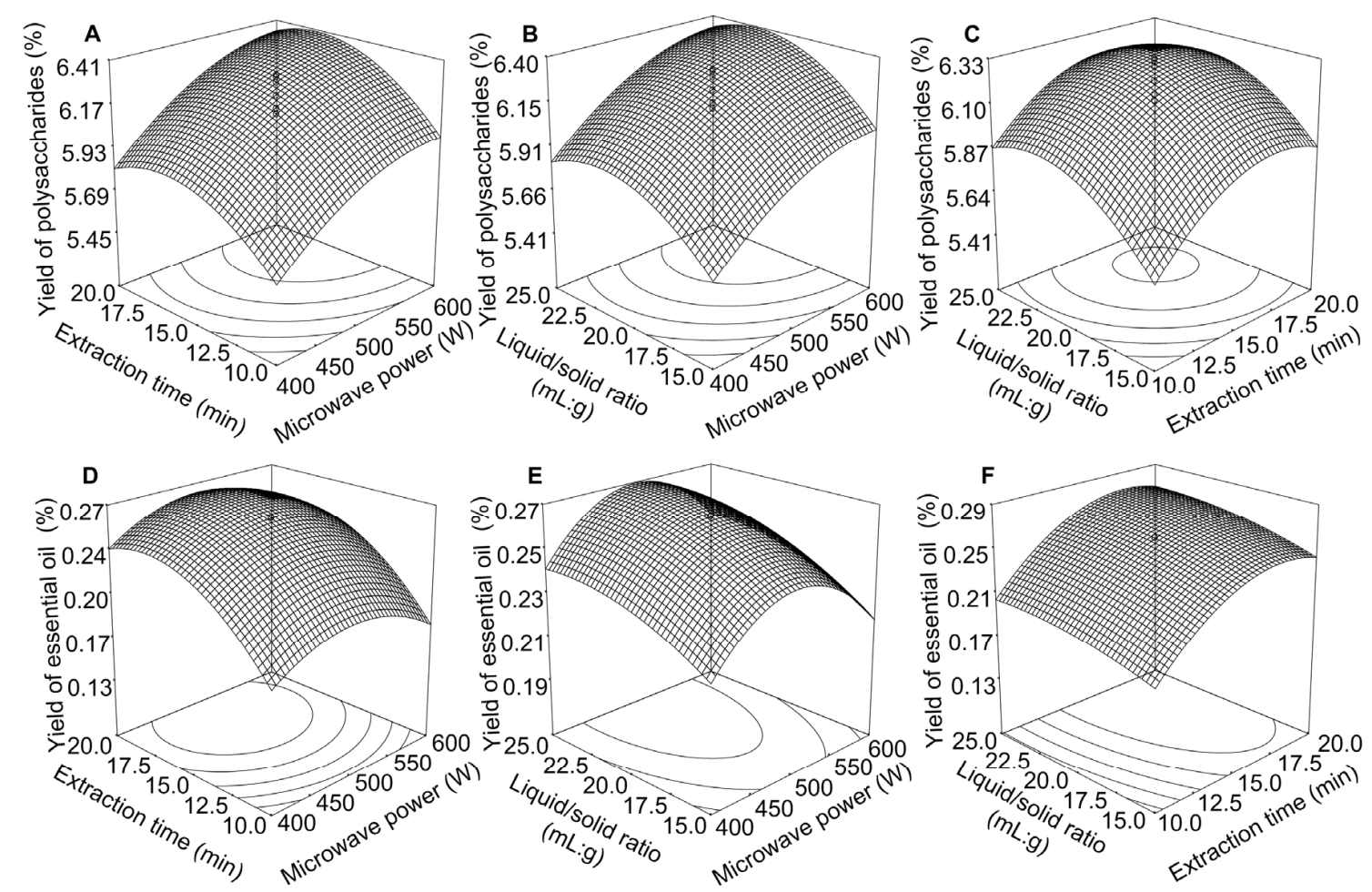

Figure 4. Response surface plots for the extraction of the polysaccharides and essential oil using the MA-SDE method: impact of the extraction time and microwave power on the yields of the polysaccharide (A) and essential oil (D); impact of the liquid/solid ratio and microwave power on the yields of the polysaccharides (B) and essential oil (E); and the effects of the liquid/solid ratio and extraction time on the yields of the polysaccharides $(\mathbf{C})$; and essential oil (F).

Based on the above model, the maximum predicted yield of the polysaccharides was $6.43 \%$, corresponding to an extraction time of $17.2 \mathrm{~min}$, liquid/solid ratio of $22.0(\mathrm{~mL} / \mathrm{g})$ and microwave power of $590 \mathrm{~W}$. The maximum predicted yield of the essential oil was predicted to be $0.28 \%$, corresponding to an extraction time of $17.7 \mathrm{~min}$, liquid/solid ratio of $23.0(\mathrm{~mL} / \mathrm{g})$, and microwave power of $504 \mathrm{~W}$. Considering the recovery yields of the polysaccharides and essential oil, the optimal conditions for extracting these materials were identified as an extraction time of $17.5 \mathrm{~min}$, liquid/solid ratio of $22.5(\mathrm{~mL} / \mathrm{g})$, and microwave power of $547 \mathrm{~W}$. Based on above the optimal conditions, a validation experiment was performed. The experimental results show that the yields of the polysaccharides and essential oil under the optimal extraction conditions were determined to be $6.39 \% \pm 0.12 \%$ and $0.27 \% \pm 0.03 \%$, respectively.

\subsection{MA-SDE Was Compared with the Traditional Extraction Methods}

Three extraction methods, including the HRE, HDE, and MA-SDE methods were compared in terms of their ability to affect the extraction of the polysaccharides and essential oil from the powdered leaves of T. chinensis var. mairei (see Figure 5). The results in Figure 5 clearly show that the yield of the polysaccharides obtained by the MA-SDE method was $6.39 \% \pm 0.12 \%$, which was 1.14 -fold higher than that of the yield obtained by the conventional HRE method. Furthermore, the yield of essential oil obtained by the MA-SDE method was $0.27 \% \pm 0.03 \%$, which was 1.23 -fold higher than the yield obtained using the conventional HDE method. The use of an extraction time of $17.5 \mathrm{~min}$ with the 
MA-SDE method provided yields that could only be achieved after 6.0 and $3.0 \mathrm{~h}$ extraction times for the HDE and HRE methods.

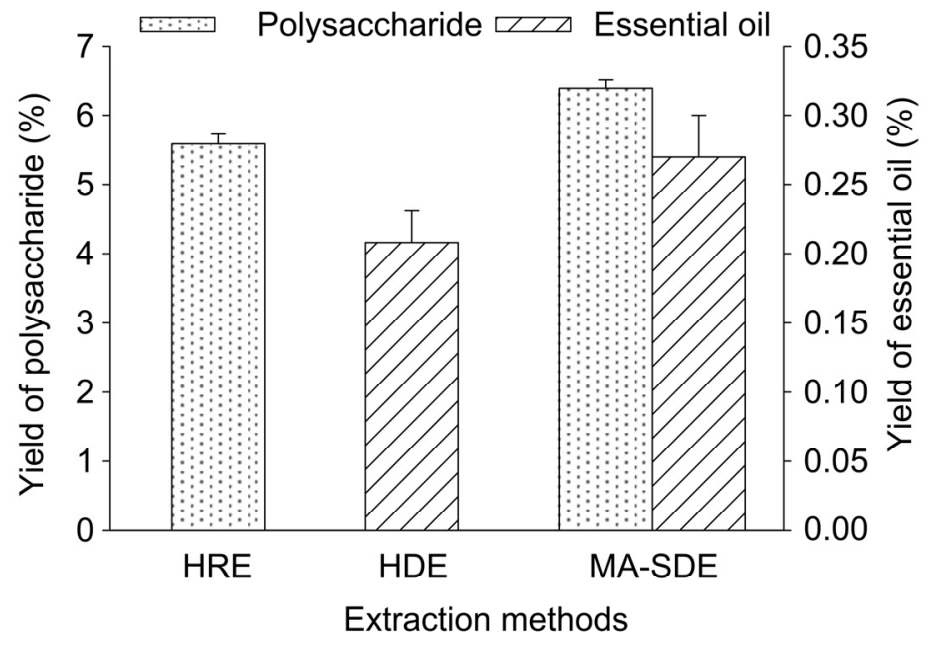

Figure 5. Effect of different extraction methods on yields of essential oil and polysaccharide. Error bars indicate standard deviation $(n=3)$.

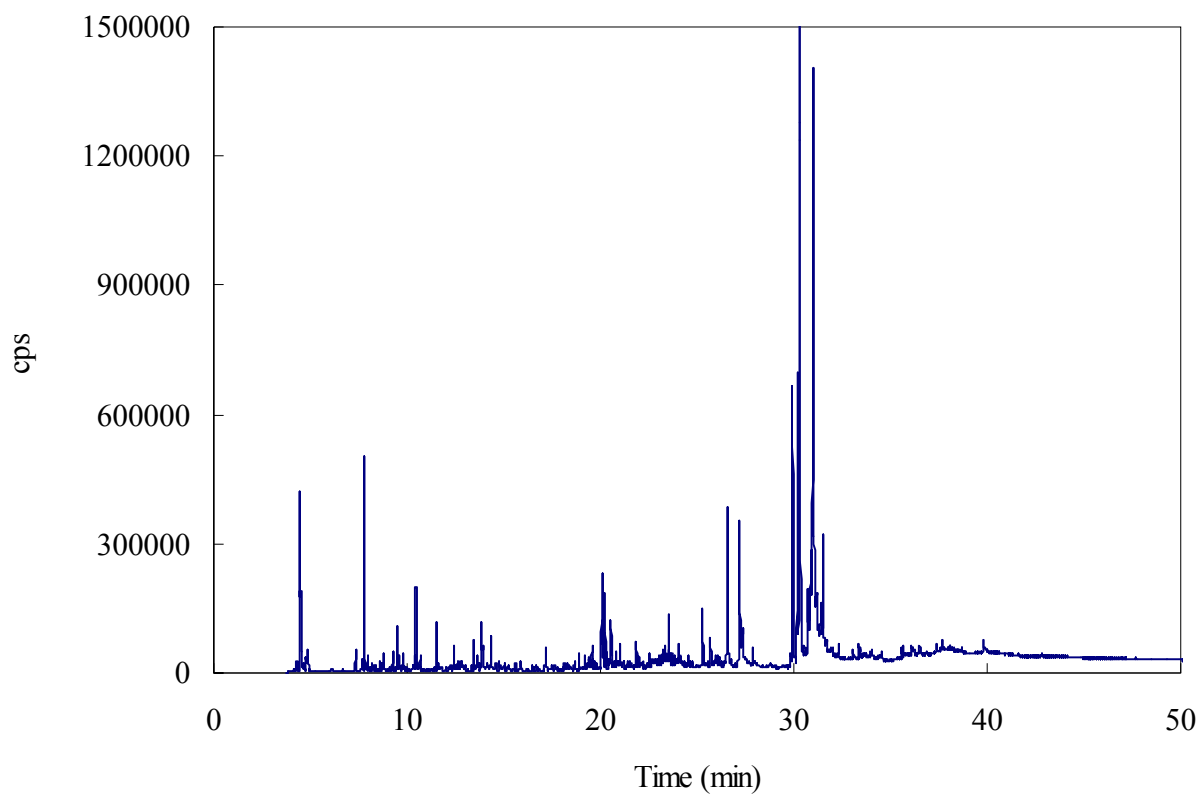

Figure 6. GC-MS chromatogram of the essential oil from the leaves of T. chinensis var. mairei.

\subsection{GC-MS Analysis of the Essential Oil Derived from the Powdered Leaves of T. chinensis var. mairei}

The components of the essential oil were identified based on a comparison of their retention indices and mass spectra with those recorded in the NIST02 Mass Spectral Library. GC-MS chromatogram of the essential oil from the leaves of T. chinensis var. mairei is shown in Figure 6. The quantitative analysis of each essential oil component (expressed as an area percentage) was carried out by peak area normalization. The components of the essential oil identified by MA-SDE and HDE are listed in Table 4. Thirty-three components were identified in the essential oil extracted from the powdered leaves of T. chinensis var. mairei using MA-SDE and HDE, accounting for $94.59 \%$ and $95.05 \%$ of the total essential oil, respectively. The compounds and contents of essential oil obtained by MA-SDE are almost the same as those obtained by HDE, and the most abundant components of the essential oil 
were determined to be fatty acids, including cis-vaccenic acid, (E)-palmitoleic acid, $n$-hexadecanoic acid, (Z,Z)-9,12-octadecadienoic acid, oleic acid, and hexanoic acid by the two methods. This means that essential oil could be extracted using MA-SDE without causing major changes in the essential oil components.

Table 4. Composition of the essential oil from T. chinensis var. mairei.

\begin{tabular}{|c|c|c|c|c|c|c|}
\hline \multirow{2}{*}{ No. } & \multirow{2}{*}{ Compound } & \multirow{2}{*}{$\begin{array}{c}\text { CAS } \\
\text { Number }\end{array}$} & \multirow{2}{*}{$\begin{array}{l}\text { Molecular } \\
\text { Formula }\end{array}$} & \multirow{2}{*}{$\mathbf{R I}^{\mathbf{a}}$} & \multicolumn{2}{|c|}{ Content $(\%)^{b}$} \\
\hline & & & & & MA-SDE & HDE \\
\hline 1 & Hexanal & $66-25-1$ & $\mathrm{C}_{6} \mathrm{H}_{12} \mathrm{O}$ & 802 & 0.26 & 0.28 \\
\hline 2 & Benzaldehyde & $100-52-7$ & $\mathrm{C}_{7} \mathrm{H}_{6} \mathrm{O}$ & 960 & 0.46 & 0.45 \\
\hline 3 & 1-Octen-3-ol & $3391-86-4$ & $\mathrm{C}_{8} \mathrm{H}_{16} \mathrm{O}$ & 978 & 0.42 & 0.42 \\
\hline 4 & Hexanoic acid & $142-62-1$ & $\mathrm{C}_{6} \mathrm{H}_{12} \mathrm{O}_{2}$ & 981 & 1.01 & 1.01 \\
\hline 5 & 3-Octanol & 20296-29-1 & $\mathrm{C}_{8} \mathrm{H}_{18} \mathrm{O}$ & 995 & 0.56 & 0.55 \\
\hline 6 & 3-Carene & $13466-78-9$ & $\mathrm{C}_{10} \mathrm{H}_{16}$ & 1010 & 0.73 & 0.72 \\
\hline 7 & Benzeneacetaldehyde & $122-78-1$ & $\mathrm{C}_{8} \mathrm{H}_{8} \mathrm{O}$ & 1045 & 0.43 & 0.42 \\
\hline 8 & 1-Octanol & $111-87-5$ & $\mathrm{C}_{9} \mathrm{H}_{18} \mathrm{O}$ & 1070 & 0.34 & 0.33 \\
\hline 9 & Nonanal & $124-19-6$ & $\mathrm{C}_{9} \mathrm{H}_{18} \mathrm{O}$ & 1102 & 1.68 & 1.68 \\
\hline 10 & 3,7-Dimethyloct-1-en-3-ol & $18479-49-7$ & $\mathrm{C}_{10} \mathrm{H}_{20} \mathrm{O}$ & 1135 & 0.43 & 0.43 \\
\hline 11 & Tetradecane & $629-59-4$ & $\mathrm{C}_{14} \mathrm{H}_{30}$ & 1400 & 0.16 & 0.16 \\
\hline 12 & $\alpha$-Ionone & $127-41-3$ & $\mathrm{C}_{13} \mathrm{H}_{20} \mathrm{O}$ & 1429 & 0.40 & 0.39 \\
\hline 13 & $\beta$-Ionone & $79-77-6$ & $\mathrm{C}_{13} \mathrm{H}_{20} \mathrm{O}$ & 1490 & 0.31 & 0.31 \\
\hline 14 & 2-Hexyl-1-decanol & $2425-77-6$ & $\mathrm{C}_{16} \mathrm{H}_{34} \mathrm{O}$ & 1504 & 1.27 & 1.27 \\
\hline 15 & Dodecanoic acid & $143-07-7$ & $\mathrm{C}_{12} \mathrm{H}_{24} \mathrm{O}_{2}$ & 1570 & 0.23 & 0.23 \\
\hline 16 & Hexadecane & $544-76-3$ & $\mathrm{C}_{16} \mathrm{H}_{34}$ & 1600 & 0.53 & 0.53 \\
\hline 17 & 2,6,10,14-Tetramethyl-pentadecane & $1921-70-6$ & $\mathrm{C}_{19} \mathrm{H}_{40}$ & 1707 & 1.87 & 1.89 \\
\hline 18 & Tetradecanoic acid & $544-63-8$ & $\mathrm{C}_{14} \mathrm{H}_{28} \mathrm{O}_{2}$ & 1770 & 0.26 & 0.25 \\
\hline 19 & Octadecane & $593-45-3$ & $\mathrm{C}_{18} \mathrm{H}_{38}$ & 1800 & 0.30 & 0.30 \\
\hline 20 & Phytane & $638-36-8$ & $\mathrm{C}_{20} \mathrm{H}_{42}$ & 1810 & 0.28 & 0.28 \\
\hline 21 & 1,2-Benzenedicarboxylic acid, bis(2-methylpropyl) ester & $84-69-5$ & $\mathrm{C}_{16} \mathrm{H}_{22} \mathrm{O}_{4}$ & 1867 & 0.88 & 0.86 \\
\hline 22 & Hexadecanoic acid methyl ester & $112-39-0$ & $\mathrm{C}_{17} \mathrm{H}_{34} \mathrm{O}_{2}$ & 1928 & 4.84 & 4.82 \\
\hline 23 & $n$-Hexadecanoic acid & $57-10-3$ & $\mathrm{C}_{16} \mathrm{H}_{32} \mathrm{O}_{2}$ & 1971 & 6.19 & 6.19 \\
\hline 24 & Eicosane & $112-95-8$ & $\mathrm{C}_{20} \mathrm{H}_{42}$ & 2000 & 1.06 & 1.08 \\
\hline 25 & Heneicosane & $629-94-7$ & $\mathrm{C}_{21} \mathrm{H}_{44}$ & 2100 & 1.01 & 1.00 \\
\hline 26 & Phytol & $150-86-7$ & $\mathrm{C}_{20} \mathrm{H}_{40} \mathrm{O}$ & 2112 & 0.27 & 0.27 \\
\hline 27 & cis-Vaccenic acid & $506-17-2$ & $\mathrm{C}_{18} \mathrm{H}_{34} \mathrm{O}_{2}$ & 2123 & 36.73 & 36.96 \\
\hline 28 & Oleic acid & $112-80-1$ & $\mathrm{C}_{18} \mathrm{H}_{34} \mathrm{O}_{2}$ & 2142 & 1.67 & 1.70 \\
\hline 29 & $(Z, Z)-9,12-$ Octadecadienoic acid & $60-33-3$ & $\mathrm{C}_{18} \mathrm{H}_{32} \mathrm{O}_{2}$ & 2156 & 1.88 & 1.83 \\
\hline 30 & (E)-Palmitoleic acid & $112-79-8$ & $\mathrm{C}_{18} \mathrm{H}_{34} \mathrm{O}_{2}$ & 2163 & 23.66 & 24.05 \\
\hline 31 & Linolenic acid ethyl ester & $1191-41-9$ & $\mathrm{C}_{20} \mathrm{H}_{34} \mathrm{O}_{2}$ & 2170 & 0.53 & 0.52 \\
\hline 32 & Ethyl oleate & $111-62-6$ & $\mathrm{C}_{20} \mathrm{H}_{38} \mathrm{O}_{2}$ & 2179 & 3.44 & 3.37 \\
\hline 33 & Eicosanoic acid, ethyl ester & $18281-05-5$ & $\mathrm{C}_{22} \mathrm{H}_{44} \mathrm{O}_{2}$ & 2380 & 0.51 & 0.50 \\
\hline Total & & & & & 94.59 & 95.05 \\
\hline
\end{tabular}

\section{Conclusions}

A MA-SDE method has been successfully developed for the simultaneous separation of the polysaccharides and essential oil from the powdered leaves of T. chinensis var. mairei. First, extraction solvent of essential oil, particle size of sample, extraction time, microwave power, and liquid/solid ratio were optimized using single factor experiment. Then, based on the single-factor experimental results, a CCD combined with RSM was used for further optimizing the microwave power, extraction time, and liquid/solid ratio. Based on the results of single factor experiments and CCD tests, the optimal conditions for the extraction of the essential oil were determined to be dichloromethane as the extraction solvent, a sample particle size of $60-80 \mathrm{mesh}$, liquid/solid ratio of $22.5 \mathrm{~mL} / \mathrm{g}$, extraction time of $17.5 \mathrm{~min}$ and microwave power of $547 \mathrm{~W}$. MAE is well known as a technique for green extraction $[39,40]$ and adheres to the technical advantages of MAE. Compared to conventional HRE and HDE methods, the MA-SDE method provided higher yields, less energy consumption, and shorter extraction duration, which suggested that this method is highly effective for the extraction of the 
polysaccharides from $T$. chinensis var. mairei. In addition, this method accelerates the isolation of essential oil from $T$. chinensis var. mairei without causing major changes in the essential oil composition. The proposed green and effective MA-SDE method could also be used for the simultaneous separation of volatile compounds and polysaccharides from other plants.

Acknowledgments: This work was financially supported by the Fundamental Research Fund for Central Universities (DL13CA06, 2572015EA04), the National Natural Science Foundation (31200478), and the Natural Science Foundation of Heilongjiang Province (C201412). We sincerely thank anonymous reviewers for their constructive comments that substantially improved the manuscript.

Author Contributions: Chunjian Zhao and Chunying Li conceived the underlying idea of the paper. Xin He, Yukun Zhang, Kaiting Wang and Yujiao Ni contributed to the practical aspects of the research work; Yujie Fu and Lei Yang analyzed the data; Xin He and Chunying Li wrote the manuscript.

Conflicts of Interest: The authors declare no conflict of interest.

\section{References}

1. Baloglu, E.; Kingston, D.G.I. The taxane diterpenoids. J. Nat. Prod. 1999, 62, 1448-1472. [CrossRef] [PubMed]

2. Fu, Y.; Li, S.; Zu, Y.; Yang, G.; Yang, Z.; Luo, M.; Jiang, S.; Wink, M.; Efferth, T. Medicinal chemistry of paclitaxel and its analogues. Curr. Med. Chem. 2009, 16, 3966-3985. [CrossRef] [PubMed]

3. $\mathrm{Wu}, \mathrm{M}$; $\mathrm{Wu}, \mathrm{Y}$. Structural characterisation of a water-soluble polysaccharide with high branches from the leaves of Taxus chinensis var. mairei. Food Chem. 2009, 113, 1020-1024. [CrossRef]

4. Yang, W.-X.; Zhao, Z.-G.; Wang, L.-H.; Yu, S.-J.; Liang, Z.-S. Control of hypertension in rats using volatile components of leaves of Taxus chinensis var. mairei. J. Ethnopharmacol. 2012, 141, 309-313. [CrossRef] [PubMed]

5. Zheng, Z.-Q.; Fu, Y.-Y.; Li, B.-H.; Zhang, M.-L.; Yang, X.-L. PSY-1, a Taxus chinensis var. mairei extract, inhibits cancer cell metastasis by interfering with MMPs. Nat. Prod. Commun. 2014, 9, 241-245. [PubMed]

6. Zhang, D.; Meng, H.; Yang, H.-S. Antidiabetic activity of Taxus cuspidata polysaccharides in streptozotocininduced diabetic mice. Int. J. Biol. Macromol. 2012, 50, 720-724. [CrossRef] [PubMed]

7. Yin, Y.; Yu, R.; Yang, W.; Yuan, F.; Yan, C.; Song, L. Structural characterization and anti-tumor activity of a novel heteropolysaccharide isolated from Taxus yunnanensis. Carbohyd. Polym. 2010, 82, 543-548. [CrossRef]

8. Zuo, Y.; Zhang, K.; Lin, Y. Microwave-accelerated derivatization for the simultaneous gas chromatographicmass spectrometric analysis of natural and synthetic estrogenic steroids. J. Chromatogr. A 2007, 1148, 211-218. [CrossRef] [PubMed]

9. Nde, D.B.; Boldor, D.; Astete, C. Optimization of microwave assisted extraction parameters of neem (Azadirachta indica A. Juss) oil using the Doehlert's experimental design. Ind. Crops Prod. 2015, 65, 233-240. [CrossRef]

10. Singh, V.; Kumar, P.; Sanghi, R. Use of microwave irradiation in the grafting modification of the polysaccharides-A review. Prog. Polymer Sci. 2012, 37, 340-364. [CrossRef]

11. Li, S.; Xu, L.; Xiong, Y.; Zhang, C. Study on microwave extraction of polysaccharides from branches of Taxus mairei (Lemee et Levl). S.Y. Hu ex Liu by response surface method. Chin. Arch. Tradit. Chin. Med. 2013, 31, 2221-2223.

12. Wang, Y.; Wang, F.; Ma, X.; Sun, S.; Leng, F.; Zhang, W.; Wang, X. Extraction, purification, characterization and antioxidant activity of polysaccharides from Piteguo fruit. Ind. Crops Prod. 2015, 77, 467-475.

13. Yuan, Y.; Macquarrie, D. Microwave assisted extraction of sulfated polysaccharides (fucoidan) from Ascophyllum nodosum and its antioxidant activity. Carbohyd. Polym. 2015, 129, 101-107. [CrossRef] [PubMed]

14. Hu, Y.; Kong, W.; Yang, X.; Xie, L.; Wen, J.; Yang, M. GC-MS combined with chemometric techniques for the quality control and original discrimination of Curcumae longae rhizome: Analysis of essential oils. J. Sep. Sci. 2014, 37, 404-411. [CrossRef] [PubMed]

15. Cassel, E.; Vargas, R.M.F.; Martinez, N.; Lorenzo, D.; Dellacassa, E. Steam distillation modeling for essential oil extraction process. Ind. Crops Prod. 2009, 29, 171-176. [CrossRef]

16. Presti, M.L.; Ragusa, S.; Trozzi, A.; Dugo, P.; Visinoni, F.; Fazio, A.; Dugo, G.; Mondello, L. A comparison between different techniques for the isolation of rosemary essential oil. J. Sep. Sci. 2005, 28, 273-280. [CrossRef] [PubMed] 
17. Okoh, O.O.; Sadimenko, A.P.; Afolayan, A.J. Comparative evaluation of the antibacterial activities of the essential oils of Rosmarinus officinalis L. obtained by hydrodistillation and solvent free microwave extraction methods. Food Chem. 2010, 120, 308-312. [CrossRef]

18. Riu-Aumatell, M.; Vargas, L.; Vichi, S.; Guadayol, J.M.; López-Tamames, E.; Buxaderas, S. Characterisation of volatile composition of white salsify (Tragopogon porrifolius L.) by headspace solid-phase microextraction (HS-SPME) and simultaneous distillation-extraction (SDE) coupled to GC-MS. Food Chem. 2011, 129, 557-564. [CrossRef]

19. Kraujalyte, V.; Leitner, E.; Venskutonis, P.R. Characterization of Aronia melanocarpa volatiles by headspace-solid-phase microextraction (HS-SPME), simultaneous distillation/extraction (SDE), and gas chromatography-olfactometry (GC-O) methods. J. Agric. Food Chem. 2013, 61, 4728-4736. [CrossRef] [PubMed]

20. Patra, J.K.; Kim, S.H.; Baek, K.-H. Antioxidant and free radical-scavenging potential of essential oil from Enteromorpha linza L. prepared by microwave-assisted hydrodistillation. J. Food Biochem. 2015, 39, 80-90. [CrossRef]

21. Benkaci-Ali, F.; Akloul, R.; Boukenouche, A.; Pauw, E.D. Chemical composition of the essential oil of Nigella sativa seeds extracted by microwave steam distillation. J. Essent. Oil Bear. Plants 2013, 16, 781-794. [CrossRef]

22. Jiao, J.; Gai, Q.Y.; Wang, W.; Luo, M.; Zhao, C.J.; Fu, Y.J.; Ma, W. Ionic-liquid-assisted microwave distillation coupled with headspace single-drop microextraction followed by GC-MS for the rapid analysis of essential oil in Dryopteris fragrans. J. Sep. Sci. 2013, 36, 3799-3806. [CrossRef] [PubMed]

23. Gavrila, I.; Gavrila, A.I.; Ivopol, M.; Ivopol, G.C.; Popescu, M.; Mircioaga, N. Microwave assisted extraction of essential oils from enzymatically pretreated lavender (Lavandula angustifolia Miller). Cent. Eur. J. Chem. 2014, 12, 829-836.

24. Ferhat, M.A.; Tigrine-Kordjani, N.; Chemat, S.; Meklati, B.Y.; Chemat, F. Rapid extraction of volatile compounds using a new simultaneous microwave distillation: Solvent extraction device. Chromatographia 2007, 65, 217-222. [CrossRef]

25. Ma, C.; Liu, T.; Yang, L.; Zu, Y.; Chen, X.; Zhang, L.; Zhang, Y.; Zhao, C. Ionic liquid-based microwaveassisted extraction of essential oil and biphenyl cyclooctene lignans from Schisandra chinensis Baill fruits. J. Chromatogr. A 2011, 1218, 8573-8580. [CrossRef] [PubMed]

26. Wang, L.; Weller, C.L. Recent advances in extraction of nutraceuticals from plants. Trends Food Sci. Technol. 2006, 17, 300-312.

27. Mandal, V.; Mohan, Y.; Hemalatha, S. Microwave assisted extraction-An innovative and promising extraction tool for medicinal plant research. Pharmacogn. Rev. 2007, 1, 7-18.

28. Council of Europe-European Directorate for the Quality of Medicines \& Healthcare. European Pharmacopoeia, 6th ed.; Council of Europe: Strasbourg, France, 2007; pp. 77-81.

29. DuBois, M.; Gilles, K.A.; Hamilton, J.K.; Rebers, P.A.; Smith, F. Colorimetric method for determination of sugars and related substances. Anal. Chem. 1956, 28, 350-356. [CrossRef]

30. Li, X.; Wang, Z.; Wang, L.; Walid, E.; Zhang, H. Ultrasonic-assisted extraction of polysaccharides from Hohenbuehelia serotina by response surface methodology. Int. J. Biol. Macromol. 2012, 51, 523-530. [CrossRef] [PubMed]

31. Chen, F.; Zu, Y.; Yang, L. A novel approach for isolation of essential oil from fresh leaves of Magnolia sieboldii using microwave-assisted simultaneous distillationand extraction. Sep. Purif. Technol. 2015, 154, 271-280. [CrossRef]

32. Veggi, P.; Martinez, J.; Meireles, M. Microwave-Assisted Extraction for Bioactive Compounds: Theory and Practice; Chemat, F., Cravotto, G., Eds.; Springer: New York, NY, USA, 2012; pp. 16-35.

33. Ćujić, N.; Šavikin, K.; Janković, T.; Pljevljakušić, D.; Zdunić, G.; Ibrić, S. Optimization of polyphenols extraction from dried chokeberry using maceration as traditional technique. Food Chem. 2016, 194, 135-142. [CrossRef] [PubMed]

34. Jin, R.; Fan, L.; An, X. Microwave assisted ionic liquid pretreatment of medicinal plants for fast solvent extraction of active ingredients. Sep. Purif. Technol. 2011, 83, 45-49. [CrossRef]

35. Gedye, R.; Smith, F.; Westaway, K. Microwaves in organic and organometallic synthesis. J. Microw. Power Electromagn. Energy 1991, 26, 1-17. 
36. Kullu, J.; Dutta, A.; Constales, D.; Chaudhuri, S.C.; Dutta, D. Experimental and modeling studies on microwave-assisted extraction of mangiferin from Curcuma amada. 3 Biotech 2014, 4, 107-120.

37. Li, Y.; Fabiano-Tixier, A.S.; Vian, M.A.; Chemat, F. Solvent-free microwave extraction of bioactive compounds provides a tool for green analytical chemistry. TrAC Trends Anal. Chem. 2013, 47, 1-11. [CrossRef]

38. Li, C.; Lu, Z.; Zhao, C.; Yang, L.; Fu, Y.; Shi, K.; He, X.; Li, Z.; Zu, Y. Ionic-liquid-based ultrasound/microwave-assisted extraction of 2,4-dihydroxy-7-methoxy-1,4-benzoxazin-3-one and 6methoxy-benzoxazolin-2-one from maize (Zea mays L.) seedlings. J. Sep. Sci. 2015, 38, 291-300. [CrossRef] [PubMed]

39. Rombaut, N.; Tixier, A.-S.; Bily, A.; Chemat, F. Green extraction processes of natural products as tools for biorefinery. Biofuels Bioprod. Bioref. 2014, 8, 530-544. [CrossRef]

40. Chemat, F.; Fabiano-Tixier, A.S.; Vian, M.A.; Allaf, T.; Vorobiev, E. Solvent-free extraction of food and natural products. TrAC Trends Anal. Chem. 2015, 71, 157-168. [CrossRef]

(C) 2016 by the authors; licensee MDPI, Basel, Switzerland. This article is an open access article distributed under the terms and conditions of the Creative Commons by Attribution (CC-BY) license (http://creativecommons.org/licenses/by/4.0/). 